\title{
ROLE PERCEPTION OF CAREER DEVELOPMENT AND SUPPORT ORGANIZATION TO ORGANIZATION COMMITMENT (Research Nurse On Health Services Agency Regional Hospital "Mardi Waluyo" Blitar East Java)
}

\section{Mudaim}

Universitas Muhammadiyah Metro

\begin{abstract}
This research was aimed at examining the role of perception of career development and organizational support on the organizational commitment. This study involved seventy nurses of Badan Pelayanan Kesehatan Rumah Sakit Daerah "Mardi Waluyo" Blitar as the subjects of the research. The research data were collected using three scales, that are, scale of perception of career development, organizational support, and organizational commitment. The hypothesis was that the organizational commitment could be predicted from the perception of career development and organizational support. The data were analyzed with multivariate regression analysis. The results of this research showed that perception of career development and organizational support had very significant role on organizational commitment $\left(F: 6.589 ; R^{2}=0.164 ; p\right.$ $=0.003$ ), beside that, perception of career development had very significant with organizational commitment $(\mathrm{F}=12.922 ; \mathrm{r}=0.161 ; \mathrm{p}=0.001)$, but the organizational support with organizational commitment was insignificant $(\mathrm{F}=$ $0.257 ; \mathrm{r}=0.003 ; \mathrm{p}=0.620$ ).
\end{abstract}

Keywords: organizational commitment, career development, organizational support.

\section{PENDAHULUAN}

Pergeseran dinamika perubahan dalam pelayanan kesehatan sekarang ini juga berdampak terhadap pergeseran nilai-nilai dalam masyarakat, pergeseran nilai-nilai dalam masyarakat harus senantiasa diantisipasi oleh para penyelenggara jasa layanan rumah sakit. Tanpa penyesuaian dengan nilai-nilai, norma-norma maupun pola tingkah laku umum masyarakat, pelayanan tidak akan diminati oleh masyarakat bahkan mungkin ditolak dan dijauhi masyarakat.
Rumah sakit dituntut untuk memberikan pelayanan yang berkualitas yang dihasilkan secara efektif dan efisien agar rumah sakit dapat bertahan dan terus berkembang serta mempunyai nilai lebih. Upaya menjaga kualitas pelayanan tersebut perlu dilakukan penelitian secara terus menerus agar diketahui kelemahan dan kekurangannya, salah satu cara untuk mengukur mutu jasa pelayanan rumah sakit adalah dengan melihat tingkat komitmen karyawan, karena tingkat komitmen karyawan 
sangat diperlukan dalam pengembangan pelayanan kesehatan, serta atas dasar komitmen atau tidaknya karyawan dalam memberikan layanan kesehatan tentunya akan mempengaruhi masyarakat dalam pemilihan kembali layanan kesehatan tersebut.

Badan Pelayanan Kesehatan Rumah Sakit Daerah "Mardi Waluyo" Blitar adalah salah satu dari lima rumah sakit yang ada di Kota Blitar yang sampai saat ini terus berusaha mengembangkan kualitas sumber daya manusia sebagai upaya untuk membantu mengatasi berbagai permasalahan kesehatan pada khususnya, peningkatan pelayanan, dan pengembangan keterampilan bagi karyawan. Penelitian ini dilakukan karena rendahnya tingkat pelayanan yang diberikan rumah sakit kepada pasien rawat inap, baik pada saat pendampingan pasien yang akan diperiksa, kurang pekanya perawat terhadap keluhan pasien yang akan melahirkan, jumlah paramedis yang terkadang tidak seimbang dengan jumlah pasien yang ada, dan rendahnya keterampilan yang dimiliki perawat. Kenyataan tersebut merupakan sesuatu yang menarik dan menimbulkan pertanyaan mengenai bentuk komitmen yang dimiliki perawat rumah sakit selama ini.

Baiknya jasa pelayanan dalam melayani kebutuhan masyarakat adalah baiknya rumah sakit tersebut secara keseluruhan dimata pasien maupun masyarakat. Sebaliknya, buruknya pelayanan dari yang diberikan adalah buruknya rumah sakit secara keseluruhan. Karenanya, perawat yang berkualitas, bekerja keras serta bersedia memberikan kinerja terbaiknya bagi organisasi mutlak adanya bagi sebuah rumah sakit. Bagaimana membentuk perawat yang bersedia memberikan kinerja terbaiknya bagi rumah sakit adalah tugas yang sangat penting bagi para pengelola rumah sakit tersebut. Salah satu cara untuk membuat karyawan bersedia bekerja keras adalah dengan menumbuhkan komitmen terhadap organisasi di kalangan mereka. Grusky menyatakan bahwa karyawan yang memiliki komitmen terhadap organisasi akan merasa dirinya terikat $/$ melekat/menyatu dengan organisasi (dalam Wahn, 1998:255). Mowday menyatakan bahwa karyawan akan menilai secara positif keterkaitannya dengan organisasi dan konsekuensi dari itu ia akan melakukan 
apa saja demi tercapainya tujuan organisasi (dalam Schappe, 1998:277).

Pelayanan prima identik dengan pelayanan yang berorientasi pada pelanggan. Pelayanan yang berorientasi pada pelanggan yang dilakukan oleh karyawan suatu organisasi merupakan suatu perilaku yang tidak terjadi dengan sendirinya. Karyawan yang berkomitmen cenderung memiliki usaha yang lebih tinggi untuk menolong pelanggan dan membuat para pelanggan lebih senang dan terpuaskan terhadap pelayanan yang diberikan (Masterson, 2001:594). Kepuasan pelanggan berhubungan sangat signifikan dengan perilaku yang berorientasi pelanggan, dan berhubungan secara signifikan dengan pemberian pelayanan standard, dukungan pegawai dan pengawas (Susskind, dkk. 2003:179). Dalam penelitian tersebut dijelaskan kepuasan pelanggan terhadap pelayanan berhubungan dengan tingkat orientasi pelanggan dari para karyawan dan menunjukkan bahwa pemberi pelayanan yang berkomitmen terhadap pelanggan cenderung membuat para pelanggannya senang lebih sering dibandingkan dengan yang tidak berkomitmen pada pelanggan.
Dalam berbagai kajiannya, para peneliti menemukan dampak kuat atau lemahnya komitmen bagi organisasi. MacKenzie, dkk. (1998:87) menemukan hubungan yang erat antara rendahnya komitmen di kalangan karyawan dengan tingginya keluarnya anggota (turnover). Keluarnya anggota yang tinggi berdampak buruk bagi organisasi karena akan menyulitkannya dalam menyusun program yang berkelanjutan disebabkan oleh berganti-gantinya orang yang menjalankan program tersebut. Sementara itu, Schappe (1998:277) mencatat bahwa komitmen yang tinggi akan mendorong karyawan untuk bekerja keras dalam menyelesaikan tugas-tugasnya dalam konteks tanggungjawabnya (in role work behavior) dan bersedia untuk melakukan aktivitas di luar tanggungjawabnya demi organisasi (extra-role work behavior).

Dari uraian di atas bisa disimpulkan bahwa untuk menumbuhkan karyawan yang bersedia untuk bekerja keras untuk organisasi bisa dilakukan melalui upaya menumbuhkan komitmen karyawan. Pertanyaannya kemudian, bagaimana komitmen dan bisa tumbuh di kalangan karyawan?.

Untuk menjawab pertanyaan tersebut, konsep pertukaran sosial (social 
exchange) bisa digunakan sebagai dasar untuk menjelaskan. Mowday menyatakan dalam teori pertukaran sosial, komitmen bisa dianggap sebagai bentuk imbal balik karyawan (employee reciprocity) atas apa yang mereka terima dari organisasi (persepsi atas dukungan organisasi) dan atas apa yang mereka rasakan selama individu bekerja dalam waktu yang relatif lama dalam organisasi (persepsi atas pengembangan karir) (dalam Miner 1988:84). Beberapa penelitian menemukan bahwa persepsi pengembangan karir dan dukungan atas organisasi adalah dua faktor yang bisa dijadikan prediktor untuk meningkatkan komitmen karyawan terhadap organisasi.

Faktor pertama, persepsi pengembangan karir, menggambarkan bahwa pengambangan karir pada dasarnya merupakan negosiasi antara organisasi dengan individu. Apabila nilai, harapan, dan tujuan karyawan dapat dipadukan atau sesuai dengan kebutuhan dan tujuan organisasi maka dapat tercipta hubungan kerja yang efisien antara karyawan dan organisasi. Moment dan Fisher menyatakan bahwa kegagalan proses negosiasi akan mengakibatkan terjadinya tidak berfungsinya penggerak karir (career drift disfunction) pada diri karyawan maupuan organisasi yang bersangkutan (dalam Glueck, 1986:72). Hubungan kerja ini terjalin dalam kualitas tinggi dan hubungan kerja yang berkualitas rendah. Hubungan kerja yang berkualitas tinggi menandakan adanya sikap positf antara karyawan terhadap organisasi dalam melihat perkembangan karir, sementara hubungan dengan kualitas rendah menandakan adanya sikap negatif karyawan terhadap organisasi dalam melihat pengembangan karir.

Faktor kedua, persepsi atas dukungan organisasi diartikan sebagai sebuah bentuk persepsi karyawan atas komitmen organisasi kepada dirinya (Hutchison, 1997:68). Definisi lain disampaikan oleh Eisenberg, dkk. (1986:500) yang mengartikannya sebagai persepsi karyawan terhadap penghargaan dan perhatian yang diberikan oleh organisasi kepadanya. Penilaian terhadap dukungan organisasi dipengaruhi oleh pengalaman karyawan berdasarkan hasil evaluasinya terhadap perlakuan organisasi kepada karyawan selama ini (Allen dan Brady 1997.316; Eisenberg, dkk, 1986:500).

Dari pemaparan tersebut di atas bisa disimpulkan bahwa tinggi rendahnya komitmen terkait dengan pengembangan karir dan dukungan organisasi yang 
karyawan rasakan. Proses hubungan ini begitu penting artinya bagi organisasi dalam hal ini adalah rumah sakit, karena persepsi pengembangan karir dan dukungan organisas berakhir pada tinggi rendahnya kinerja karyawan ataupun organisasi teradap kualitas pelayanan yang diberikan kepada pasien.

Memperhatikan uraian di atas, perlu kiranya untuk ditelaah lebih lanjut tentang beberapa faktor yang mempengaruhi komitmen karyawan terhadap organisasi, yaitu seberapa besar peran persepsi pengembangan karir dan dukungan organisasi terhadap komitmen organisasi pada perawat BPK RSD "Mardi Waluyo" Blitar?.

\section{METODE PENELITIAN}

Subyek populasi dalam penelitian ini adalah perawat dengan status kepegawaian PNS (Pegawai Negeri Sipil) pada Badan Pelayanan Kesehatan Rumah Sakit Daerah (BPK RSD) "Mardi Waluyo" Blitar. Karyawan yang dijadikan sebagai subyek pada penelitian ini berjumlah 70 orang perawat yang memiliki ciri-ciri sebagai berikut:

1. Mempunyai masa kerja 3 tahun dengan asumsi bahwa selama masa kerja tersebut subyek telah cukup mengalami dan mempertimbangkan bebagai faktor dalam organisasi yang mempengaruhi pembentukan komitmen;

2. Memiliki tingkat pendidikan D3, yang merupakan tingkat pendidikan minimal bagi perawat yang bekerja pada rumah sakit;

3. Berusia kurang dari 55 tahun, dengan asumsi bahwa batas usia tersebut merupakan usia produktif. Subyek masih memiliki kesempatan yang besar untuk mengembangkan diri dan mempunyai alternatif dalam menentukan pekerjaannya.

Dalam penelitian ini, metode yang digunakan dalam mengumpulkan data adalah metode angket berbentuk skala. Metode angket digunakan untuk variabel bebas dan variabel tergantung, yaitu angket komitmen organisasi, angket persepsi pengembangan karir, angket dukungan organisasi.

Teknik statistik yang digunakan untuk menganalisis data penelitian adalah regresi ganda dengan dua prediktor untuk mengetahui sumbangan kedua variabel bebas terhadap variabel tergantung dilanjutkan dengan korelasi parsial untuk mengetahui korelasi antara salah satu variabel bebas dengan variabel tergantung yang lebih bersih dengan cara mengontrol pengaruh satu variabel bebas 
lainnya. Dilanjutkan dengan analisis multivariat untuk mengetahui hubungan masing-masing faktor dengan tiap-tiap variabel $\mathrm{Y}$ sehingga akan diketahui faktor mana yang lebih tinggi peranannya terhadap peningkatan komitmen organisasi. Keseluruhan proses analisis data pada penelitian ini menggunakan program SPS (Seri Program Statistika) 2000 edisi Sutrisno Hadi dan Yuni Pamardiningsih, versi IBM/IN, hak cipta (c) 2003, dilindungi UU.

\section{HASIL DAN PEMBAHASAN}

\section{Hasil Uji Hipotesis Mayor.}

Hasil model penelitian ini menunjukkan hubungan yang sangat signifikan antara persepsi pengembangan karir dan dukungan organisasi dengan komitmen organisasi pada perawat Badan Pelayanan Kesehatan Rumah Sakit Daerah "Mardi Waluto" Blitar dengan $\mathrm{F}$ sebesar 6.589, koefisien determinasi sebesar $\mathrm{R}^{2}=0.164$, dan $\mathrm{p}$ 0.003 , artinya persepsi pengembangan karir dan dukungan organisasi berperan terhadap komitmen organisasi. Variabel persepsi pengembangan karir dan dukungan organisasi dapat memprediksi komitmen organisasi pada perawat BPK
RSD "Mardi Waluyo" Blitar dengan bobot sumbangan efektif sebesar 16.4 persen.

\section{2.. Hipotesis Minor}

Hasil analisis regresi menunjukkan hasil yang sangat signifikan antara persepsi pengembangan karir dengan komitmen organisasi, dengan $\mathrm{F}=12.922 ; \mathrm{R}^{2}=$ $0.161 ; \mathrm{p}=0.001$, artinya bahwa hipotesis minor pertama diterima, persepsi pengembangan karir berperan terhadap komitmen organisasi, dengan kata lain bahwa persepsi pengembangan karir dapat memprediksi komitmen organisasi. Sumbangan efektif persepsi pengembangan adalah sebesar 16.1 persen pada komitmen organisasi.

Hasil analisis regresi menunjukkan bahwa hipotesis minor kedua ditolak, hal ini dibuktikan dengan nilai $F=0.257 ; R^{2}=0.003 ; p=0.620$, artinya dukungan organisasi tidak berperan terhadap komitmen organisasi, dengan kata lain bahwa dukungan organisasi tidak dapat memprediksi komitmen organisasi. Dukungan organisasi memberikan sumbangan efektif tergolong kecil, yaitu 0.321 persen pada komitmen organisasi. 
3. Analisis regresi multivariat, faktorfaktor persepsi pengembangan karir dan faktor-faktor dukungan organisasi terhadap komitmen organisasi

Berdasarkan hasil analisis multivariat antara faktor-faktor persepsi pengembangan karir dan faktor-faktor dukungan organisasi terhadap komitmen organisasi diperoleh hasil sebagai berikut:

\section{a. Hasil analisa regresi model penuh} terhadap komitmen afektif

Terdapat peran yang sangat signifikan antara faktor-faktor persepsi pengembangan karir dan faktor-faktor dukungan organisasi terhadap komitmen afektif, diketahui $\mathrm{F}=2,783 ; \mathrm{p}=0,007$. Hasil tersebut memperlihatkan bahwa faktor-faktor persepsi pengembangan karir dan faktor-faktor dukungan organisasi berperan terhadap komitmen afektif. Berdasarkan hasil penelitian besarnya koefesien determinasi adalah $\mathrm{R}^{2}=0,320$; atau dengan bobot sumbangan efektif sebesar 32.0 persen.

\section{b. Hasil analisa regresi model penuh terhadap komitmen kontinuansi}

Tidak terdapat peran yang signifikan antara faktor-faktor persepsi pengembangan karir dan faktor-faktor dukungan organisasi terhadap komitmen kontinuansi, diketahui $\mathrm{F}=1,550 ; \mathrm{p}=$ 0,145. Hasil tersebut memperlihatkan bahwa faktor-faktor persepsi pengembangan karir dan faktor-faktor dukungan organisasi tidak berperan terhadap komitmen kontinuansi. Berdasarkan hasil penelitian besarnya koefesien determinasi adalah $\mathrm{R}^{2}=0,208$; atau dengan bobot sumbangan efektif sebesar 20,8 persen.

\section{c. Hasil analisa regresi model penuh terhadap komitmen normatif}

Terdapat peran yang signifikan antara faktor-faktor persepsi pengembangan karir dan faktor-faktor dukungan organisasi terhadap komitmen normatif, diketahui $\mathrm{F}=2,605 ; \mathrm{p}=0,011$. Hasil tersebut memperlihatkan bahwa faktor-faktor persepsi pengembangan karir dan faktor-faktor dukungan organisasi berperan terhadap komitmen normatif. Berdasarkan hasil penelitian besarnya koefesien determinasi adalah $\mathrm{R}^{2}=0,306$; atau dengan bobot sumbangan efektif sebesar 30.6 persen.

\section{d. Hasil analisa regresi model penuh multivariat komposit terhadap komitmen organisasi}

Terdapat peran yang signifikan antara faktor-faktor persepsi pengembangan karir dan faktor-faktor dukungan organisasi terhadap komitmen 
organisasi, diketahui $\mathrm{F}=2.558 ; \mathrm{p}=$ 0,011. Hasil tersebut memperlihatkan bahwa faktor-faktor persepsi pengembangan karir dan faktor-faktor dukungan organisasi berperan terhadap komitmen organisasi. Berdasarkan hasil penelitian besarnya koefesien determinasi adalah $\mathrm{R}^{2}=0.305$; atau dengan bobot sumbangan efektif sebesar 30.5 persen.

\section{e. Hasil analisa regresi model penuh multivariat produk terhadap komitmen organisasi}

Terdapat peran yang sangat signifikan antara faktor-faktor persepsi pengembangan karir dan faktor-faktor dukungan organisasi terhadap komitmen organisasi, diketahui $\mathrm{F}=2.661 ; \mathrm{p}=$ 0.010. Hasil tersebut memperlihatkan bahwa faktor-faktor persepsi pengembangan karir dan faktor-faktor dukungan organisasi berperan terhadap komitmen organisasi. Berdasarkan hasil penelitian besarnya koefesien determinasi adalah $\mathrm{R}^{2}=0.311$; atau dengan bobot sumbangan efektif sebesar 31.1 persen.

\section{KESIMPULAN}

\section{A. Kesimpulan}

Hasil analisis pada hipotesis pertama dapat disimpulkan bahwa persepsi pengembangan karir dan dukungan organisasi secara bersama-sama berperan meningkatkan komitmen organisasi. Besarnya sumbangan efektif persepsi pengembangan karir dan dukungan organisasi terhadap komitmen organisasi adalah sebesar 16,437 persen. Hasil penelitian tersebut juga menunjukkan bahwa pengembangan karir dan dukungan organisasi yang dipersepsikan perawat rumah sakit mempunyai peran terhadap tinggi rendahnya komitmen organisasi.

Hasil analisis pada hipotesis kedua dapat disimpulkan bahwa persepsi pengembangan karir berperan meningkatkan komitmen organisasi. Pengembangan karir yang dipersepsikan perawat dapat meningkatkan komitmen organisasi setelah mengendalikan dukungan organisasi, makin positif persepsi pengembangan karir yang dirasakan makin meningkatkan komitmen perawat terhadap rumah sakit, besarnya peran persepsi pengembangan karir terhadap peningkatan komitmen organisasi adalah sebesar 16,116 persen.

Hasil analisis pada hipotesis ketiga dapat disimpulkan bahwa dukungan organisasi memiliki peran yang rendah terhadap komitmen organisasi. Dukungan organisasi yang dipersepsikan 
perawat tidak berperan terhadap komitmen organisasi setelah mengendalikan pengembangan karir, makin rendah dukungan organisasi yang dirasakan akan rendah pula komitmen perawat terhadap rumah sakit, sumbangan relatif dukungan organisasi terhadap peningkatan komitmen organisasi tergolong kecil yaitu 0,32 persen.

Secara faktorial, hasil analisis korelasi dan parsial dapat disimpulkan bahwa faktor-faktor yang berperan terhadap komitmen afektif, yaitu; program awal ketenagakerjaan dengan sumbangan efektif sebesar 5,466 persen; program pengembangan sebesar 7,559 persen; penghargaan sebesar 2,246 persen; dan kondisi kerja sebesar 15,701 persen. Faktor-faktor yang berperan terhadap komitmen kontinuansi, yaitu; jasa informasi dengan sumbangan sebesar 9,512 persen; program pengembangan sebesar 1,546 persen; keadilan prosedural sebesar 4,689 persen; dan kondisi kerja sebesar 4,014 persen. Faktor-faktor yang berperan terhadap komitmen normatif, yaitu; jasa informasi dengan sumbangan sebesar 21,711 persen; penghargaan sebesar 5,580 persen; dan kondisi kerja sebesar 1,609 persen. Faktor-faktor yang berperan terhadap komitmen organisasi pada analisis regresi multivariat komposit, yaitu; faktor jasa informasi dengan sumbangan sebesar 19,155 persen; program pengembangan sebesar 2,751 persen; dan kondisi kerja sebesar 6,936 persen. Faktor-faktor yang berperan terhadap komitmen organisasi pada analisis regresi multivariat produk, yaitu; faktor jasa informasi dengan sumbangan sebesar 21,077 persen; keadilan prosedural sebesar 1,235 persen; dan kondisi kerja sebesar 6,945 persen.

\section{B. Saran}

Berdasarkan hasil analisis, pembahasan, dan kesimpulan, maka diajukan beberapa saran sebagai berikut:

\section{Saran Bagi BPK RSD "Mardi Waluyo" Blitar}

Ada beberapa saran yang peneliti ajukan bagi BPK RSD "Mardi Waluyo" Blitar berkaitan dengan hasil penelitian.

a. Bagi instansi disarankan untuk meningkatkan pengembangan karir dan dukungan organisasi pada individu agar organisasi lebih efektif. Terutama faktor yang memberikan sumbangan efektif cukup besar yaitu faktor program awal ketenagakerjaan, 
jasa informasi, program pengembangan dan kondisi kerja dengan cara instansi sering memberikan saran pada perawat mengenai target yang ingin dicapai dalam waktu tiga bulan ke depan, memberikan apresiasi berupa kemudahan dalam jenjang kenaikan pangkat dan faktor-faktor tersebut dapat dipertahankan menjadi bagian dari tujuan, visi, dan misi yang dibangun dan dikembangkan BPK RSD "Mardi Waluyo" Blitar sehingga berdampak pada pemberian pelayanan yang baik kepada pasien.

b. Perlunya memberdayakan sarana penilaian diri dan program penilaian yang jelas dalam setahun sekali untuk melihat perkembangan masingmasing perawat dan sekaligus sebagai pertimbangan kenaikan angka kridit, adanya konseling untuk individu, adanya dukungan dari instansi untuk memberi tanggungjawab yang lebih besar kepada perawat, serta meningkatkan keterampilan sebagai upaya untuk menumbuhkan komitmen perawat sehingga tujuan-tujuan rumah sakit dapat tercapai.

\section{Saran Bagi Peneliti Selanjutnya}

Berdasarkan analisis data, variabel persepsi pengembangan karir dan dukungan organisasai memberi kontribusi sumbangan sebesar 16,4 persen terhadap komitmen perawat di rumah sakit sehingga masih terdapat faktor-faktor lain yang berperan, yaitu sebesar 83,6 persen. Dengan mengacu pada hasil tersebut maka disarankan bagi penelitian berikutnya agar mengkaji faktor-faktor lain yang berperan terhadap komitmen perawat di rumah sakit. Apabila ada yang berkeinginan menggunakan skala persepsi pengembangan karir, dukungan organisasai, dan komitmen organisasi hendaknya menyempurnakan skala tersebut agar mendapatkan hasil yang lebih baik.

\section{DAFTAR PUSTAKA}

Allen, M.W. \& Brady, R.M. 1997. Total Quality Management, organizational commitment, perceived organizational support, and intraorganizational communication. Management Communication Quarterly, 10, 316-341 
Eisenberger, R., Huntington, R., Hutchinson, S., dan Sowa,D. 1986. Perceived Organizational Support. Journal of Applied Psychology, 71: 500-500.

Glueck, W.F. 1986. Personnal: A Diagnostic Approach. Texas: Business Publishing. Inc.

Hutchinson, S. 1997. Perceived organizational support: further evidence of construct validity. Educational and Psychological Measurement, 57, 1025- 1034

MacKinzie, S.B., Podsdakoff, P.M., \& Ahearne, M. 1998. Some possible antecedents and consequences of in-role and extra-role salesperson performance. Journal of Marketing, 62, 87-98

Masterson, S.S. 2001. A Trickle-Down of Organizational Justice : Relating Employees And Customers' Perceptions of and Reactions to Fairness. Journal of Applied Psychology. 86 (4), 594604.

Meyer, J.P., dan Herscovitch, L. 2002. Commitment to Organization Change: Extension of a TheeComponent Model. Journal of Applied Psychology. 73,474-487.

Miner, J.B. 1988. Organizational Behavior: Performance and Productuvity. New York: Random House, Inc

Schappe, S.P. 1998. The influence of job satisfaction, organizational commitment and fairness perceptions on organizational citizenship behavior. The Journal of Psychology, 132, 277-290
Susskind, A.M., Kacmar, K.M. \& Borchgrevink, C.P. 2003. Customer Service Providers' Attitudes Relating to Customer Service and Customer Satisfaction in the CustomerServer Exchange. Journal of Applied Psychology. 88 (1), 179187.

Wahn, J.C. 1998. Sex differences in the continuance component of organizational commitment. Group and Organization Management, 23, 255-266 